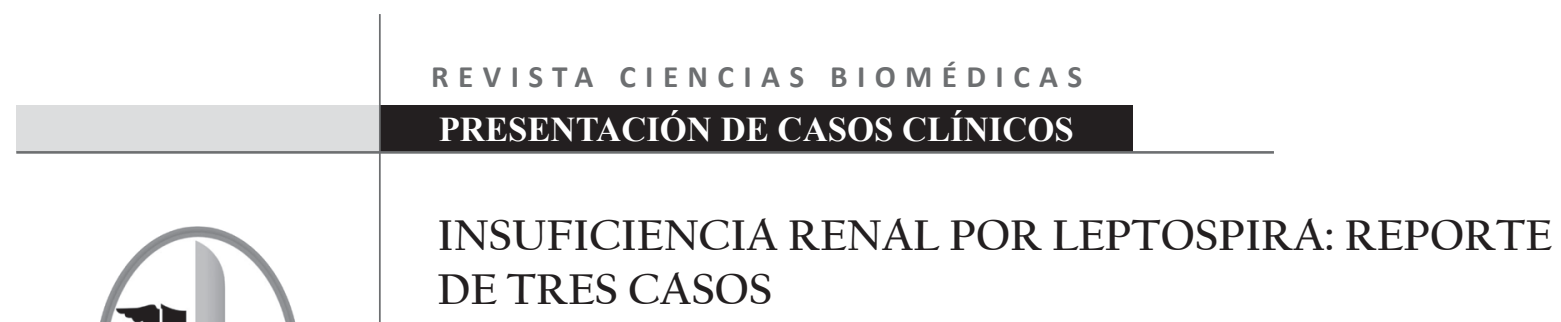

RENALFAILURE BY LEPTOSPIRA: REPORT OF THREE CASES

Morales Contreras Carol ${ }^{1}$

Arias Díaz Antonio ${ }^{1}$

Simahan Lastra Nasly ${ }^{1}$

Julio Barrios Emil ${ }^{2}$

Correspondencia: carolmoralescontreras@hotmail.com

Recibido para evaluación: enero - 12 -2011. Aceptado para publicación: marzo-2-2011

\title{
RESUMEN
}

La leptospirosis es una infección sistémica aguda, causada en la mayoría de los casos por la Espiroqueta Leptospira Interrogans, con un amplio espectro clínico. La edad de presentación es variable, siendo más frecuentemente afectado el grupo de adolescentes y adultos jóvenes. En pediatría las características clínicas de mayor relevancia son alteraciones del sensorio, dificultad respiratoria e ictericia. Presentamos tres casos de pacientes con afección renal secundaria a leptospirosis y un resumen de la literatura relacionada. Rev.cienc.biomed. 2011; 2 (1): 111-115

\section{PALABRAS CLAVES}

Leptospirosis. Síndrome de Weil. Criterios de severidad. Pediatría.

\section{SUMMARY}

Leptospirosis is an acute systemic disease, with a wide clinic spectrum, caused by Spirochete Leptospira Interrogans in most cases. The age of presentation is variable, being more frequently in teenagers and young adults. In pediatrics, the most important clinics features are depressed level of consciousness, respiratory symptoms and jaundice. We present three cases of renal injury by leptospirosis and a review of the literature. Rev.cienc.biomed. 2011; 2 (1): 111-115

\section{KEY WORD}

Leptospirosis. Weil Syndrome. Severity criteria. Pediatrics

\footnotetext{
Médico. Estudiante de Postgrado. Pediatría. Facultad de Medicina. Universidad de Cartagena. Colombia.

2 Médico. Especialista en Nefrología Pediátrica. Docente Departamento de Pediatría. Profesor Titular. Facultad de Medicina. Universidad de Cartagena. Colombia.
} 


\section{INTRODUCCIÓN}

La leptospirosis es una entidad causada por espiroquetas del género Leptospira variedad Interrogants, que agrupa 23 serogrupos y 210 serovariedades, cuyo reservorio fundamentalmenteson los roedores, caninos, ganado porcino, caballos y animales silvestres como murciélagos. Los mecanismos de trasmisión son el contacto directo con componentes sanguíneos, tejidos u orina de animales infectados o por contacto de piel y mucosas con agua contaminada $(1,2,3,4,5)$.

Existe un alto subdiagnóstico por la inespecificidad de la sintomatología en los casos leves y anictericos (5). En Colombia se estima una alta tasa de infección. En un estudio adelantado por investigadores del Caribe colombiano se encontró una seroprevalencia en trabajadores agrícolas del $13.1 \%(4)$, sin contar con estadísticas de la población general ni pediátrica.

Sus formas de presentación son la leptospirosis anictérica (80-90\%) y el síndrome de Weil (5-10\%), en este último, después de una fase de cuatro a siete días, caracterizada por fiebre, escalofríos, mialgias, dolor abdominal, conjuntivitis, entre otras, es seguida de una fase de diez a treinta días, en donde se hace manifiesta insuficiencia renal y otras complicaciones como miocarditis y edema pulmonar agudo $(1,2,3)$.

\section{CASO No .1}

Paciente de tres años y nueve meses, procedente de un barrio marginado de Cartagena, Colombia, traído a consulta pediátrica por presentar tres días de episodios febriles intermitentes, no cuantificados, que cedían parcialmente con antipiréticos. Su lugar de residencia está ubicado en área con alta densidad de roedores y cercanía a canales de drenaje de aguas negras En días anteriores presentó deposiciones líquidas, sin moco ni sangre, en moderada cantidad, asociado a vómitos alimenticios, postprandiales y sin dolor abdominal. Había recibido manejo con sales de rehidratación oral, acetaminofén y trimetropinsulfametoxazol. La sintomatología persistió y se acompañó de intolerancia progresiva a la vía oral. Ingresó con signos vitales estables, en regular estado general, ligeramente deshidratado y mínimo edema en parpados superiores. Resto de examen físico dentro de límites normales. Se realizó diagnóstico de gastroenteritis y se adelantó manejo con líquidos endovenosos. Durante la estancia hospitalaria se documentó oliguria, edema progresivo en miembros inferiores y en región facial y cifras de tensión arterial normal. Los estudios para clínicos mostraron anemia normocítica, hipocrómica, trombocitopenia (43.000 células $/ \mathrm{mm}^{3}$ ), consumo del complemento (C3: $53 \mathrm{mg} / \mathrm{dL}$ VR: $90-180 \mathrm{mg} /$ dL, C4 $72.3 \mathrm{mg} / \mathrm{dL}$ VR: $90-180 \mathrm{mg} / \mathrm{dL})$. Se diagnostica insuficiencia renal aguda oligúrica secundaria a probable síndrome hemolítico urémico. Entre los diagnósticos diferenciales se consideró síndrome nefrítico e infección urinaria. Se instaura manejó con líquidos parenterales y ceftriaxona a $100 \mathrm{mg} / \mathrm{K} /$ día. Se realizaron intentos fallidos para forzar diuresis con furosemida. Al día siguiente por el incremento progresivo de los azoados y oliguria es trasladada a Unidad de Cuidados Intermedios. Durante su estancia hospitalaria, se instaló ictericia, documentándose hiperbilirubinemia a expensas de la directa, parcial de orina con $\mathrm{pH}$ 5,0. Densidad 1010, hemoglobina xxx, leucocitos 30-35/c, hematíes campos llenos, cilindros granulosos 0-2 / c, hialinos 0-2 / c, céreos 0-2 / c. PCR $91 \mathrm{mg} / \mathrm{dL}$, test de Coombs directo negativo y pruebas de coagulación normal. Con los antecedentes epidemiológicos se sospechó Enfermedad de Weil, lo cual fue confirmado por serología IgM positivo para leptospira. Como hallazgo agregado se encontró CPK total elevada en $662 \mathrm{u} / \mathrm{L}$. Desde el tercer día, se apreció mejoría de la diuresis, con reducción rápida de azoados y niveles de bilirrubinas. Se presentó recuperación de la trombocitopenia, desaparición de edemas y regreso a lo normal de la tensión arterial. Se conservó la hospitalización hasta culminar el esquema de siete días de antibióticos. Tabla No 1.

\section{CASO $\mathrm{N}^{\circ} .2$}

Paciente masculino de trece años, procedente de zona rural de Bolívar, Colombia. Consulta por cuadro de mialgias generalizadas y dolor abdominal tipo cólico, no irradiado y asociado 


\begin{tabular}{|c|c|c|c|c|c|}
\hline \multicolumn{7}{|c|}{ TABLA No 1 } \\
Día & $\begin{array}{c}\text { Creati- } \\
\text { nina } \\
\mathrm{mg} / \mathrm{dL}\end{array}$ & $\begin{array}{c}\text { BUN } \\
\mathrm{mg} / \mathrm{dL}\end{array}$ & $\begin{array}{c}\text { Urea } \\
\mathrm{mg} / \\
\mathrm{dL}\end{array}$ & $\begin{array}{c}\text { Bilirru- } \\
\text { bina } \\
\text { Total } \\
\mathrm{mg} / \mathrm{dL}\end{array}$ & $\begin{array}{c}\text { Bilirru- } \\
\text { bina } \\
\text { Directa } \\
\mathrm{mg} / \mathrm{dL}\end{array}$ \\
\hline 1 & 2.87 & 36.4 & 23.8 & $=$ & $=$ \\
\hline 2 & 3.04 & 39 & $=$ & 11.8 & 9.3 \\
\hline 3 & 2.87 & 45.6 & $=$ & $=$ & $=$ \\
\hline 4 & 3.32 & 51.4 & 110 & 8.7 & 7.04 \\
\hline 5 & 1.22 & 37.9 & 81.1 & $=$ & $=$ \\
\hline 6 & 1.17 & 26.5 & $=$ & $=$ & $=$ \\
\hline 7 & 0.76 & 16 & 34.2 & 3.45 & 1.10 \\
\hline 8 & 0.47 & 11.8 & 25.3 & $=$ & $=$ \\
\hline
\end{tabular}

a náuseas. Al ingreso a sala de urgencia se aprecia en mal estado general, quejumbroso, taquicárdico, taquipneico, con deshidratación, ictericia, cifras tensionales elevadas y oliguria. El interrogatorio a familiares documenta posible factor epidemiológico positivo para leptospirosis. Los para clínicos de ingreso muestran anemia normocítica, normocrómica, trombocitopenia, hiperbilirrubinemia no conjugada, elevación de CPK total, alteración del sedimento urinario y de las pruebas de función renal. Prueba de Ig. M positiva para leptospira, compatibles con síndrome de Weil. Se inicia manejo con ceftriaxona a dosis convencionales y medidas de sostén. Presenta rápido incremento de azoados, sin alteraciones electrolíticas y oliguria que no responde a infusión de furosemida por lo que se inicia manejo con diálisis peritoneal. Desde el tercer día de terapia dialítica se aprecia descenso de azoados (creatinina $4.55 \mathrm{mg} / \mathrm{dL}$, BUN $62.86 \mathrm{mg} / \mathrm{dL}$, urea 134,5 $\mathrm{mg} / \mathrm{dl})$. Presenta evolución satisfactoria con normotensión y estabilización de azoados. Al culminar terapia antibiótica es dado de alta con recomendaciones y seguimiento por la consulta externa de nefrología.

\section{CASO No .3}

Paciente masculino de seis años, procedente de zona rural del departamento de Bolívar, Colombia- Traído por presentar fiebre de ocho días, mialgias, artralgias, vómitos alimenticios y orina colúrica. En los antecedentes socioeconómicos se precisa residencia en zona carente de servicios básicos y convivencia en hacinamiento. Al ingreso se encontró normotenso, con deshidratación, anasarca (incluso edema escrotal), inyección
TABLA NO 2

CASO NO 3 ESTUDIOS PARACLINICOS

\begin{tabular}{|c|c|}
\hline Hemograma & $\begin{array}{l}\mathrm{Hg}: 10.4 \mathrm{mg} / \mathrm{dl}, \mathrm{Hto} 31,2 \% \text {, } \\
\text { plaquetas } 470.000\end{array}$ \\
\hline Electrolitos & $\begin{array}{l}\text { Sodio } 131.9 \mathrm{mg} / \mathrm{dl} \text {, Potasio } 6.10 \\
\mathrm{mg} / \mathrm{dl} \text {, cloro } 98.8 \mathrm{mg} / \mathrm{dl}\end{array}$ \\
\hline Urianalisis & $\begin{array}{l}\text { Densidad 1015, pH 5,0. } \\
\text { Proteínas trazas. Leucocitos } \\
\text { 4.6xc. Hematíes } 1-3 \times c \text {. }\end{array}$ \\
\hline Función renal & \begin{tabular}{|l|} 
Creatinina $2.74 \mathrm{mg} / \mathrm{dL}$. BUN \\
$38.93 \mathrm{mg} / \mathrm{dL}$. Urea $83.3 \mathrm{mg} / \mathrm{dl}$. \\
\end{tabular} \\
\hline Ot & $\begin{array}{l}\text { Proteínas totales } 5.2 \mathrm{mg} / \\
\text { dl. Albumina } 3.2 \mathrm{mg} / \mathrm{dl} \text {. Perfil } \\
\text { lipídico normal. }\end{array}$ \\
\hline
\end{tabular}

conjuntival y ausencia de déficit neurológico. Con sospecha de síndrome nefrótico se solicitaron para clínicos. Tabla No 2.

Con estos hallazgos se descartó síndrome nefrótico. Se sospecha insuficiencia renal no oligúrica a leptospirosis. CPK total: 357 $\mathrm{mg} / \mathrm{dl}$. Manejado con penicilina cristalina; se confirmó diagnóstico con serología Ig. M positiva para leptospira. Culminó esquema antibiótico con normalización de azoados y electrolitos.

\section{DISCUSIÓN}

La leptospirosis es una zoonosis endémica en los países pobres, en donde las condiciones ambientales y socioculturales favorecen la multiplicación de los agentes trasmisores. En este reporte de casos los pacientes cuentan con factores epidemiológicos positivos, fundamentalmente la carencia del adecuado saneamiento básico de sus viviendas y poblaciones de residencias $(1,9,11,12)$.

La falla renal por leptospirosis por lo general se presenta en adultos, entre $40-60 \%$ de los casos, más frecuente durante la segunda semana de evolución. Se manifiesta como una nefritis intersticial aguda, sin oliguria, con alteraciones en el sedimento urinario, proteinuria en rango no nefrótico, en algunos casos piuria y hematuria, asociado frecuentemente a ictericia y trombocitopenia. En otros casos se puede detectar la presencia de leptospiras en el sedimento hasta cuatro semanas después de la infección. Algunos autores $(5,6,13)$ citan la posibilidad de necrosis tubular aguda. Se han dilucidado varios mecanismos fisiopatológicos: alteraciones hemodinámicas, hipovolemia por 
vómitos, diarrea o aumento de pérdidas insensibles por la fiebre, injuria directa sobre el glomérulo, vasculitis y en ocasiones rabdomiolisis. Las principales alteraciones son la nefritis intersticial, con infiltrado mononuclear y en algunos casos necrosis tubular aguda. Por lo general la insuficiencia renal es de tipo no oligúrica, siendo frecuente la hipocalemia.

En modelos animales se han determinado afección en dos bombas importantes: el intercambiador sodio/hidrogeno 3 (NH3) ubicado en el túbulo proximal, cuya alteración explica la fracción excretada de sodio elevada y la poliuria en la fase inicial de la enfermedad y el incremento en la expresión del trasportador sodio/ potasio/ 2 cloro $(\mathrm{NaK} 2 \mathrm{Cl})$ del asa de Henle como respuesta compensadora $(5,6)$.

Algunos autores $(5,6$,$) han descrito como$ criterios de mal pronóstico para la leptopirosis: oligoanuria, trombocitopenia, shock, creatinina plasmática $>3 \mathrm{mg} / \mathrm{dl}$, potasio plasmático > $4 \mathrm{mEq} / \mathrm{L}$ y la auscultación torácica anormal.

A pesar de los avances en el manejo y el relativo rápido acceso a las terapias de reemplazo renal, la mortalidad varía del $1 \%$ al 20\%, incrementándose después de tres días de establecida la disfunción. Por ello la mejor estrategia es el diagnóstico temprano y tratamiento oportuno.

Las recomendaciones para el tratamiento se basan en antibióticos betalactámicos. Se puede utilizar cefotaxime, doxiciclina y azitromicina, que tienen igual efectividad en el grupo de betalactámicos. $(7,8)$.

La evolución de la falla renal por leptospirosis es variable y depende de los factores pronósticos y el establecimiento oportuno de las medidas terapéuticas. Los casos de insuficiencia renal aguda anictérica pueden recuperarse dentro de pocos días sin requerir diálisis. Desde un punto de vista general los azoados y las plaquetas se recuperan en dos semanas, la proteinuria y la depuración de la creatinina en tres meses y la concentración urinaria en seis meses.

El presente reporte de casos permite observar la variabilidad en la presentación clínica de la leptospirosis y la repercusión sobre el aparato renal. En dos de ellos pese a contar con síntomas clásicos, el diagnóstico fue de exclusión, además el método confirmatorio correspondió a la serología Ig M para leptospiras, estudio que tiene sensibilidad de 32 - $72 \%$, que puede considerarse no contundente (5).

El compromiso renal de la leptospirosis en estos pacientes fue diverso: la paciente del primer caso cursó con un síndrome de Weil atípico por la edad, fuera del rango inferior descrito en la literatura, insuficiencia renal oligúrica antes de la segunda semana. A pesar que poseía factores de mal pronóstico (oliguria, trombocitopenia, niveles altos de creatinina), evolucionó satisfactoriamente, con restauración de la función renal en la primera semana de la enfermedad.

En el segundo caso observamos adolescente con sintomatología clásica que desarrolló falla renal oligúrica, requiriendo diálisis peritoneal $y$ en tercer caso una insuficiencia renal no oligúrica, todos con respuesta adecuada. Es de anotar que ninguno exhibió alteración del sensorio, shock ni compromiso respiratorio que son las manifestaciones más frecuentes en el grupo pediátrico $(5,6,10)$.

\section{CONCLUSIONES}

Es conveniente mantener sospecha diagnóstica de leptospirosis en casos de síndromes febriles en todos los grupos de edad. Instaurar rápidas medidas terapéuticas, incluso terapias de reemplazo renal, realizar seguimiento multidisciplinario y propender en las distintas localidades por la instauración de eficaces medidas de saneamiento ambiental. Además se hace necesario ampliar los estudios implementando la realización del MAT (test de microaglutinación) y el aislamiento bacteriano por cultivo en los medios de Ellinghausen-McCullough-Johnson-Harris 0 Fletcher, procedimientos recomendados por la OMS como pilares en el diagnóstico.

CONFLICTOS DE INTERÉS: ninguno que declarar.

FINANCIACIÓN: recursos propios de los autores. 


\section{REFERERENCIAS BIBLIOGRÁFICAS}

1. Bharti A, Nally J, Ricaldi J, et al. Leptospirosis Consortium Leptospirosis: azonotic disease of global Importance. Lancet Infect Dis. 2003; 3: 757 - 771.

2. Raghavan $P$, Subbupoongothai $R$, Yung-Fu Ch. Leptospirosis: pathogenesis, immunity, and diagnosis. Curr Opin Infect Dis. 2007; 20: $284-292$.

3. McBride A, Athanazio D, Mitermayer R, et al. Leptospirosis. Curr Opin Infect Dis. 2005; 18: $376-386$.

4. Nájera S, Alvis N, Babilonia D, Alvarez L, et al. Leptospirosis ocupacional en una región del Caribe colombiano. Salud Pública Mex. 2005; 47: 240 - 244.

5. Andrade L, De Francesco E, Seguro A. Leptospiral Nephropathy. Seminars in Nephrology. 2008; 28 (4): 383 - 394.

6. Abdulkader R, Silva M. The kidney in leptospirosis. Pediatr Nephrol. 2008; 23: $2111-2120$.

7. Thanachai $P$, Somnuek $D$, Asda $V$, et al. Ceftriaxone compared with sodium penicillin $G$ for treatment of severe Leptospirosis. Clinical Infectious Diseases. 2003; 36: 1507-1513.

8. Matthew G, Duane H, Clinton M. Antimicrobial therapy of leptospirosis. Current Opinion Infect Dis. 2006, 19: 533-537.

9. Pappas G, Papadimitriou P, Siozopoulou V, et al. The globalization of leptospirosis: worldwide incidence trends. International Journal of Infectious Diseases. 2008; 12(2): 351-357.

10. Vega L. Leptospirosis en niños: Parece común pero infrecuente, extraña paradoja. Rev. Mex Pediatr. 2006; 73(1): $3-4$.

11. Vanasco N.B, Schmeling MF, Lottersberger J. Clinical characteristics and risk factors of human leptospirosis in Argentina(1999-2005). Acta Tropical. 2008; 107: 255 - 258.

12. Leptospirosis. Oficina General de Epidemiología / Instituto Nacional de Salud, Ministerio de Salud del Perú. 2000.

13. Pérez J. Hallazgos histopatológicos en necropsias de leptospirosis. Colombia Médica. 1997; $28(1): 4-8$.

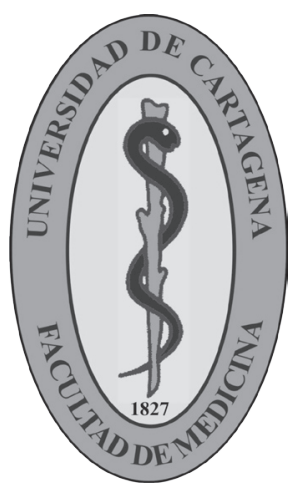

\section{GRUPO DE INVESTIGACIÓN: UNIMOL}

LÍNEAS: Alteraciones metabólicas y patologías relacionadas con obesidad. Biología Molecular en Enfermedades Genéticas e infecciosas. Estrategias y Gestión Educativa en Medicina. Farmacología Molecular y Bioquímica. Mecanismos de regulación de la expresión génica. Medicina Tropical. STEM Cell

Email: degomez@hotmail.com 